This is an electronic reprint of the original article. This reprint may differ from the original in pagination and typographic detail.

\author{
Author(s): Küüsmaa, Maria; Schumann, Moritz; Sedliak, Milan; Kraemer, William J.; Newton, \\ Robert; Malinen, Jari-Pekka; Häkkinen, Arja; Häkkinen, Keijo; Nyman, Kai
}

Title: $\quad$ Effects of morning versus evening combined strength and endurance training on physical performance, muscle hypertrophy and serum hormone concentrations

Year: $\quad 2016$

Version:

Please cite the original version:

Küüsmaa, M., Schumann, M., Sedliak, M., Kraemer, W. J., Newton, R., Malinen, J.-P., Häkkinen, A., Häkkinen, K., \& Nyman, K. (2016). Effects of morning versus evening combined strength and endurance training on physical performance, muscle hypertrophy and serum hormone concentrations. Applied Physiology, Nutrition, and Metabolism, 41(12), 1285-1294. https://doi.org/10.1139/apnm-2016-0271

All material supplied via JYX is protected by copyright and other intellectual property rights, and duplication or sale of all or part of any of the repository collections is not permitted, except that material may be duplicated by you for your research use or educational purposes in electronic or print form. You must obtain permission for any other use. Electronic or print copies may not be offered, whether for sale or otherwise to anyone who is not an authorised user. 


\title{
Effects of morning vs. evening combined strength and endurance training on physical performance, muscle hypertrophy and serum hormone concentrations
}

\author{
Maria Küüsmaa ${ }^{1}$, Moritz Schumann ${ }^{1}$, Milan Sedliak ${ }^{2}$, William J. Kraemer ${ }^{3}$, Robert U. Newton ${ }^{4}$, \\ Jari-Pekka Malinen ${ }^{1}$, Kai Nyman ${ }^{5}$, Arja Häkkinen ${ }^{5,6}$, Keijo Häkkinen ${ }^{1}$ \\ ${ }^{1}$ Department of Biology of Physical Activity, University of Jyväskylä, Jyväskylä, Finland; \\ ${ }^{2}$ Faculty of Physical Education and Sport, Comenius University in Bratislava, Bratislava, \\ Slovakia; ${ }^{3}$ Department of Human Sciences, The Ohio State University, Columbus, OH, USA; \\ ${ }^{4}$ Exercise Medicine Research Institute, Edith Cowan University, Joondalup, Australia; ${ }^{5}$ Central \\ Hospital of Central Finland, Jyväskylä, Finland; ${ }^{6}$ Department of Health Sciences, University of \\ Jyväskylä, Jyväskylä, Finland
}

\author{
Corresponding author: \\ Maria Küüsmaa (maria.kuusmaa@jyu.fi) \\ ${ }^{1}$ Department of Biology of Physical Activity, University of Jyväskylä, Finland \\ P.O. Box 35, 40014, Jyväskylä, Finland \\ Tel: +358408281288; Fax: +358142602071
}

\section{Co-authors:}

Moritz Schumann (moritz.schumann@jyu.fi)

Milan Sedliak (milan.sedliak@fsport.uniba.sk)

William J. Kraemer (kraemer.44@osu.edu)

Robert Newton (r.newton@ecu.edu.au)

Jari-Pekka Malinen (jari-pekka.j-p.mailinen@student.jyu.fi)

Kai Nyman (kai.nyman@ksshp.fi)

Arja Häkkinen (arja.h.hakkinen@jyu.fi)

Keijo Häkkinen (keijo.hakkinen@jyu.fi) 


\begin{abstract}
This study investigated the effects of 24 weeks of morning vs. evening same-session combined strength (S) and endurance (E) training on physical performance, muscle hypertrophy and resting serum testosterone and cortisol diurnal concentrations. Forty-two young men were matched and assigned to a morning (m) or evening (e) $\mathrm{E}+\mathrm{S}$ or $\mathrm{S}+\mathrm{E}$ group $(\mathrm{mE}+\mathrm{S} n=9, \mathrm{mS}+\mathrm{E} n=9, \mathrm{eE}+\mathrm{S} n=12$ and $\mathrm{eS}+\mathrm{E} \mathrm{n}=12$ ). Participants were tested for dynamic leg press 1 repetition maximum (1RM) and time to exhaustion $\left(\mathrm{T}_{\mathrm{exh}}\right)$ during an incremental cycle ergometer test both in the morning and evening, cross-sectional area (CSA) of vastus lateralis and diurnal serum testosterone and cortisol concentrations $(7: 30 \mathrm{~h} ; 9: 30 \mathrm{~h} ; 16: 30 \mathrm{~h} ; 18: 30 \mathrm{~h})$. All groups similarly increased 1RM in the morning $(14-19 \% ; \mathrm{p}<0.001)$ and evening $(18-24 \%$; $<<0.001)$. CSA increased in all groups by week $24(12-20 \%, \mathrm{p}<0.01)$, however, during the training weeks 13-24 the evening groups gained more muscle mass (time-of-day main effect; $\mathrm{p}<0.05$ ). $\mathrm{T}_{\text {exh }}$ increased in all groups in the morning $(16-28 \% ; \mathrm{p}<0.01)$ and evening $(18-27 \% ; \mathrm{p}<0.001)$, however, a main effect for the exercise order, in favor of $\mathrm{E}+\mathrm{S}$, was observed on both testing times $(\mathrm{p}<0.051)$. Diurnal rhythms in testosterone and cortisol remained statistically unaltered by the training order or time. The present results indicate that combined strength and endurance training in the evening may lead to larger gains in muscle mass, while the $\mathrm{E}+\mathrm{S}$ training order might be more beneficial for endurance performance development. However, training order and time seem to influence the magnitude of adaptations only when the training period exceeded 12 weeks.
\end{abstract}

Keywords: time-of-day, testosterone, cortisol, concurrent training, order effect, muscle crosssectional area 


\section{INTRODUCTION}

Previous studies have shown that when performed simultaneously, adaptations to strength and endurance training might be compromised (Cadore et al. 2013, Chtara et al. 2005, Gravelle and Blessing 2000, Hickson 1980). However, both training types are necessary for general health and fitness and for time saving purposes these training modes are sometimes performed during the same training session. When combined into the same session, the intra-session sequence of strength and endurance training may be one factor influencing the training adaptations (Cadore et al. 2013; Chtara et al. 2005; Gravelle \& Blessing 2000). It has been proposed that the first mode of exercise may cause fatigue and, thereby, negatively influence the quality and quantity of the second mode of exercise (Leveritt \& Abernethy 1999), and/or hamper the acute molecular responses (Fyfe et al. 2014). It has been demonstrated that strength performance (Cadore et al. 2013) or neural adaptations (Eklund et al. 2015) might be interfered, when endurance training constantly precedes strength training, especially when the training period is prolonged. Others have observed compromised gains in endurance performance due to the intra-session sequence of strength and endurance training (Chtara et al. 2005; Gravelle \& Blessing 2000). However, a number of studies have suggested that the intra-session sequences of strength and endurance training may not influence the training adaptations in strength and endurance performance or in muscle mass gains (Chtara et al. 2008; Schumann et al. 2014).

In addition to the training mode specificity, adaptations in strength and endurance performance may also be dependent on the time-of-day when the training is performed. Previous studies have shown that greater improvements in maximal strength performance occur at the time-of-day at which resistance training was regularly performed (Chtourou et al. 2012, Sedliak et al. 2008, Souissi et al. 2002). The time-of-day-effect on training-induced hypertrophic adaptations has 
received less attention. Although Sedliak et al. (2009) found no statistically significant differences in the magnitude of muscular hypertrophy after strength training between morning and evening training, a tendency for smaller gains in muscle size were reported when repeatedly performing strength training in the morning. The literature about endurance performance, on the other hand, has led to inconclusive results. Although some studies have suggested that the adaptations to endurance performance are time-of-day-specific (Hill et al. 1998; Torii et al. 1992), others disagree (Hill et al. 1989).

Testosterone (T) and cortisol (C) are considered as important biomarkers in exercise science. One of the main functions of $\mathrm{T}$ is to maintain anabolism, in addition to other tissues, also within the muscular system by promoting protein synthesis. C, however, has been shown to have catabolic function that promotes protein breakdown (Kraemer and Ratamess 2005). Therefore, some studies have suggested $\mathrm{T}$ and $\mathrm{C}$ to be potent hormones contributing to long-term changes in performance and muscle growth (Ahtiainen et al. 2003; Häkkinen et al. 1985), while others may disagree (West and Phillips 2012). The effects of both prolonged strength as well as endurance training on basal $\mathrm{T}$ and $\mathrm{C}$ concentrations, however, have shown to be inconsistent or non-existent (Hackney et al. 2003; Kraemer et al. 1995; Kraemer \& Ratamess 2005), whereas the data about the effects of combined strength and endurance training are limited. In addition, both $\mathrm{T}$ and $\mathrm{C}$ exhibit circadian rhythmicity with morning peaks and evening nadirs (Kraemer et al. 2001). Greater $\mathrm{T}$ and $\mathrm{C}$ responses have been observed in afternoon compared with morning strength training sessions (Chtourou et al. 2013). Nevertheless, the influence of short term strength training protocols have shown to be insufficient to alter the circadian profile of $\mathrm{T}$ and $\mathrm{C}$ (Häkkinen et al. 1988, Kraemer et al. 2001). Sedliak et al. (2007) have observed decreased serum $\mathrm{C}$ concentrations after prolonged time-of-day-specific strength training in the morning. However, 
they suggested that decreased anticipatory psychological stress before the morning test sessions rather than adaptations in the adrenal cortex induced by regular training in the morning caused these adaptations. Neither morning nor evening training time showed any influence on the rhythms in T concentrations (Sedliak et al. 2007). Therefore, further examination is needed to confirm whether exercise training can exert a strong enough influence to alter the circadian rhythms of T and C (Teo et al. 2011).

The purpose of the present study was to examine how the strength and endurance training sequence and time-of-day (i.e. morning vs. evening) affect the adaptations in muscle strength and hypertrophy as well as endurance performance after 24 weeks of time-of-day-specific samesession combined strength and endurance training. In addition, we wanted to determine whether such training regimens performed in the morning or evening have an effect on diurnal patterns of resting serum $\mathrm{T}$ and $\mathrm{C}$ concentrations. Since strength and endurance training are often performed concurrently, it was important to understand whether the morning or evening training time or specific strength and endurance training order can optimize the adaptations to combined training.

\section{METHODS}

\section{Participants}

Seventy-two men who had no history of previous strength or endurance training over the past year were recruited for this study. The participants were considered healthy and had no medical contraindications or musculoskeletal restrictions that could affect the results of this study. In addition, a cardiologist checked each participant's health questionnaire and ECG. According to the Munich Chronotype Questionnaire (Roenneberg et al. 2003) none of the participants 
belonged to an extreme morning or evening chronotype. Shift and night workers were excluded. After receiving a thorough explanation of the purpose and risks of the study, the participants provided written consent before participation. This study complied with the Declaration of Helsinki and was approved by the Ethics Committee in the University of Jyväskylä.

Some dropouts occurred during the 24-week intervention period due to medical issues, motivation or personal reasons, i.e. change of residence. Thus, only the participants who successfully completed at least $90 \%$ of the entire 24 -week training intervention were included in the analyses $(\mathrm{n}=52)$.

\section{Study design and measurements}

The summary graph with the study design and measurements are presented on Figure 1. The 24week combined strength (S) and endurance (E) training consisted of two 12-week periods which were separated with the pre-, mid- and post-measurements performed during a non-training week. Pre-measurements took place in September/October before the trainings had started, midmeasurements was conducted after 12 weeks of training in January/February and postmeasurements in May/June after completing 24 weeks of combined training. During the first part of the intervention period (wk 1-12) participants trained two times per week $[2 \mathrm{x}(1 \mathrm{E}+1 \mathrm{~S})$ or $2 \mathrm{x}(1 \mathrm{~S}+1 \mathrm{E})]$ and during the second part of the intervention (wk 13-24) an additional session was added every two weeks so that all participants performed 5 training sessions in a 2-week period $[5 \mathrm{x}(1 \mathrm{E}+1 \mathrm{~S})$ or $5 \mathrm{x}(1 \mathrm{~S}+1 \mathrm{E})]$ to allow further progression in training adaptations. Following the basal measurements for strength and endurance performance, participants were matched into four training groups based on the anthropometrics (Table 1) and strength and endurance performance at baseline (Table 2): (i) training in the morning (m) and performing endurance training always before the strength training $(\mathrm{mE}+\mathrm{S}, \mathrm{n}=9)$, (ii) training in the morning with strength always 
preceding endurance training $(\mathrm{mS}+\mathrm{E}, \mathrm{n}=9)$, (iii) training in the evening (e) and performing endurance before strength training $(\mathrm{eE}+\mathrm{S}, \mathrm{n}=12)$, (iv) training in the evening with strength always preceding endurance training $(e S+E, n=12)$. The controls $(n=10)$ were asked to maintain their pre-experimental physical activity level throughout the study. A nutritional information lecture was held for the participants before the start of the study to instruct them to consume nutrients according to the national guidelines. Participants were asked to keep their daily energy intake and habitual physical activities constant throughout the intervention period and avoid any additional strength and/or endurance training.

Strength and endurance measurements were conducted both in the morning (between 06:30 $\mathrm{h} \pm$ $30 \mathrm{~min}$ and 9:30 $\mathrm{h} \pm 30 \mathrm{~min}$ ) and in the evening (between 16:30 $\mathrm{h} \pm 30 \mathrm{~min}$ and 19:30 $\mathrm{h} \pm 30$ min) independent of the group assignment. The morning and evening tests were carried out in a random order across all participants. Within individuals, the tests were always carried out in the same order and at the same time-of-day $( \pm 1 \mathrm{~h})$ at all three measurement points. The time interval between two consecutive strength or endurance performance tests was at least 36 hours and participants were asked to avoid any unnecessary physical activity. The last training session and the first measurement were always separated by a minimum of two and maximum of four days. The participants received instructions to follow their usual sleeping habits with a minimum of 6 hours of sleep taken on the night preceding each testing session. They were asked to avoid alcohol for 24 hours and caffeine for 12 hours before the endurance and strength performance tests. A familiarization session was carried out for all participants before the start of the 24-week intervention on a non-training-specific time-of-day. This session included familiarization to the dynamic leg press testing procedures and measuring the starting knee angle for the dynamic leg press $\left(\sim 60^{\circ}\right)$. After the familiarization session the device settings were stored for further 
measurements to ensure the correct device set ups for each subject throughout the study. In addition, a small mark was tattooed to the mid-point (between the greater trochanter of the femur and lateral joint space) of the lateral side of the right thigh to ensure the repeatability of the ultrasound measurements for muscle cross-sectional area throughout the study.

One repetition maximum (1 $\mathbf{R M})$ : Maximal bilateral concentric leg press strength was measured by a horizontal leg press (knee angle $\sim 60^{\circ}$ ) (David 210, David Health Solutions Ltd., Helsinki, Finland). Before commencing maximum efforts a short warm-up was performed $(5 \times 70 \% ; 3 \times 80 \%$ and $2 \times 90 \%$ of the predicted $1 \mathrm{RM})$. A minimum of three and maximum of five trials of single repetitions (1 RM) were allowed. Each trial was separated with one minute of rest. The testing continued until the participant was unable to extend legs to a full extension of $180^{\circ}$.

Cross-sectional area of vastus lateralis (CSA) was assessed by a B-mode axial-plane ultrasound (SSD- $\alpha 10$, Aloka Co Ltd, Tokyo, Japan) with the extended-field-of-view mode (23$\mathrm{Hz}$ sampling frequency) using a $10 \mathrm{MHz}$ linear array probe (Ahtiainen et al. 2010). Three panoramic images were taken at $50 \%$ of femur length (marked during the familiarization session). During the measurements participants laid in the supine position, with lower limbs extended and resting in a styrofoam knee support. A line, representing the mid-point, was drawn across the thigh, perpendicular to the measurement table. The probe was manually moved in an axial plane from the lateral to the medial side of the thigh along the drawn line. Images were manually analyzed with the ImageJ software (National Institute of Health, USA, version 1.44) by manually tracing along the border of the $\mathrm{m}$. vastus lateralis. The mean of the two closest values was used for further statistical analysis. The measurements always took place in the morning at the same time of the day $( \pm 1 \mathrm{~h})$. All the measurements and analysis were done by the same 
technician, who was aware of the subject's ID but the ID did not reveal the group to which the subject belonged to.

Time to exhaustion $\left(\mathbf{T}_{\mathbf{e x h}}\right)$ : The graded maximal aerobic cycling test to volitional exhaustion was performed on a mechanically braked bicycle ergometer (Ergomedic 839E, Monark Exercise $\mathrm{AB}$, Sweden). The exercise intensity was increased by $25 \mathrm{~W}$ every two minutes starting with 50W. Pedaling frequency was required to be maintained at $70 \mathrm{rpm}$ throughout the test. The participants were verbally encouraged to continue cycling until exhaustion. The test was stopped when the participant was unable to keep up the required pedaling frequency.

\section{Serum hormone concentrations}

Venous blood samples were collected during one day at 7:30 $\mathrm{h} \pm 30 \mathrm{~min}, 9: 30 \mathrm{~h} \pm 30 \mathrm{~min}, 16: 30$ $\mathrm{h} \pm 30 \mathrm{~min}$ and $18: 30 \mathrm{~h} \pm 30 \mathrm{~min}$ at pre-, mid- and post-measurements. Participants were asked to keep two days of rest before the day when the blood samples were drawn. Physical activity during that day was also asked to be kept as low as possible, however, the subjects were allowed to leave the lab in between the blood samples drawn and have a normal working day. Participants were asked to fast 12 hours before the first blood sample, after which a standardized breakfast was provided. They were instructed to consume another light meal at around 12:00 13:00 h. Thereafter, participants were asked to avoid food until the last two blood samples (16:30 $\mathrm{h} \pm 30 \mathrm{~min}$ and $18: 30 \mathrm{~h} \pm 30 \mathrm{~min}$ ) were drawn.

Venous blood samples $(\sim 10 \mathrm{ml})$ for the determination of serum total $\mathrm{T}$ and $\mathrm{C}$ concentration were collected by a qualified laboratory technician from an antecubital vein with a vacutainer and test tubes (Vacuette, Greiner Bio-OneGmbH, Kremsmünster, Austria) containing appropriate preservatives. Samples were centrifuged at $3500 \mathrm{rpm}$ (Heraus Megafuge $1.0 \mathrm{R}$, Gendro 
Laboratory Products, Hanau, Germany) for $10 \mathrm{~min}$, plasma harvested and all samples were stored at $-80^{\circ} \mathrm{C}$ until assayed. Analysis of total $\mathrm{T}$ and $\mathrm{C}$ was performed using chemical luminescence techniques (Immunlite 2000, Simens Healthcare, Diagnostics Products Ltd., Llanberies, UK) and hormone specific immunoassay kits (Siemens, New York City, NY, USA). The sensitivities for serum T and $\mathrm{C}$ were: $0.5 \mathrm{nmol} \cdot \mathrm{L}^{-1}$ and $5.5 \mathrm{nmol} \cdot \mathrm{L}^{-1}$, respectively. The intraassay coefficients of variation were $8.3 \%$ and $5.3 \%$ for $\mathrm{T}$ and $\mathrm{C}$, respectively. The inter-assay coefficients of variation were $9.1 \%$ for $\mathrm{T}$ and $7.2 \%$ for $\mathrm{C}$.

\section{Exercise training programs}

Training consisted of two 12-week progressive same-session combined strength and endurance training periods either in the morning or in the evening. The morning training groups $(\mathrm{mE}+\mathrm{S}$ and $\mathrm{mS}+\mathrm{E}$ ) performed all training sessions between 6:30-10:00h, while the evening training groups $(\mathrm{eE}+\mathrm{S}$ and $\mathrm{eS}+\mathrm{E})$ performed their training sessions between 16:30-20:00h. The training programs were identical for the $\mathrm{E}+\mathrm{S}$ and $\mathrm{S}+\mathrm{E}$ group independent of the training time, only the sequence of strength and endurance training was reversed. Endurance and strength training were combined into the one training session so that no more than a 5-10 minute break was allowed during the two training sections. The duration of the combined endurance and strength training sessions progressively increased from 60 to 120 minutes. All the training sessions were supervised.

Strength training consisted of exercises aimed at improving both maximal strength and muscle hypertrophy and was planned as a whole body periodized program with the main focus on knee extensors and flexors as well as hip extensors. Each training session consisted of three lowerbody exercises: bilateral dynamic leg press, seated dynamic knee extension and flexion. Four to five exercises were performed for other main muscle groups (lateral pull down, standing bilateral 
triceps push down, bilateral biceps curl, seated military press, or bilateral dumbbell fly, trunk flexors and extensors). Strength training was designed to improve muscular endurance in the first 4 weeks, which was performed as circuit training (intensity $40-70 \%$ of $1 \mathrm{RM}$ ). The subsequent 4 weeks (weeks 5-8) were designed to produce muscle hypertrophy (intensity $70-85 \%$ of 1 RM) and followed by 4 weeks (weeks 9-12) of mixed hypertrophic and maximal strength training (intensity $75-95 \%$ of $1 \mathrm{RM}$ ) (Table 3). A similar strength training program with slightly higher intensities was carried out also during the second 12 weeks of training.

Endurance training was carried out on cycle ergometers and the training intensity was based on the maximum heart rate $\left(\mathrm{HR}_{\max }\right)$ determined during the training-time-specific graded maximal incremental cycling test. For the first 12 weeks of training the pre-training test results were used. For training weeks 13-24 the training heart rate zones were readjusted according to the results obtained from the mid-measurements. Endurance training sessions averaged from 30-50 minutes. Interval $\left(85-100 \%\right.$ of $\left.\mathrm{HR}_{\max }\right)$ and continuous $\left(65-80 \%\right.$ of $\left.\mathrm{HR}_{\max }\right)$ training protocols were performed weekly. Interval training consisted of $4 \times 4$ min high-intensity intervals $(85-100 \%$ of $\mathrm{HR}_{\max }$ ), which were separated by 4 min active resting periods $\left(70 \%\right.$ of $\left.\mathrm{HR}_{\max }\right)$. During the first training period both interval and continuous training sessions were performed once a week, whereas during the second training period, when the training frequency increased, one additional high-intensity interval training session was added. Participants were instructed to maintain a constant pedaling cadence (around $70 \mathrm{rpm}$ ) while the resistance on the cycle ergometer was adjusted in accordance with heart rate (Polar FT7, Polar Electro Oy, Kempele, Finland). 


\section{Statistical analyses}

Data are presented as mean \pm SD. Normality of the data was checked and subsequently confirmed using the Shapiro-Wilk test. Effects of the time-of-day-specific training on strength and endurance performance as well as on resting serum hormone concentrations and muscle hypertrophy were examined by a two-factor general linear model (GLM) with univariate ANOVA by using absolute changes. Time-of-day of the training and training order were set as fixed factors when appropriate. Within-group changes over time in the morning and in the evening were examined by using absolute values with repeated measures GLM, where Time, with 3 levels (4 levels for hormonal data analysis) was the only factor. Morning and evening differences at pre-, mid- and post-measurements in performance variables were checked by using paired samples T-tests. In addition, to analyse associations between strength performance and muscle mass Pearson correlation coefficients were calculated. Area under the curve (AUC) was calculated for $\mathrm{T}$ and $\mathrm{C}$ concentrations by using the following equation:

$$
\left.\mathrm{AUC}=\left[\left(\mathrm{y}_{1}+\mathrm{y}_{2}\right) / 2\right) \times\left(\mathrm{t}_{1}-\mathrm{t}_{2}\right)\right]
$$

where $\mathrm{y}_{1}$ and $\mathrm{y}_{2}$ are the consecutive resting $\mathrm{T}$ or $\mathrm{C}$ concentrations and the time separating the two measurement time-points. AUC was calculated for the total period between 7:30 and 18:30. Statistical significance was accepted at a criterion alpha level of $p<0.05$, whereas values $\mathrm{p} \leq 0.06$ were accepted as a significant trend. Effect size (d) for pairwise comparisons is reported as Cohen's $d$ with an effect size of $\geq 0.20$ being considered as small, $\geq 0.50$ as medium and $\geq 0.80$ as large. 


\section{RESULTS}

At baseline no between-group differences were found in strength and endurance performance or in anthropometrics. Absolute values of strength or endurance performance variables did not show significant morning to evening differences in any group at any measurement time point.

\section{Dynamic strength performance}

Morning measurements: $1 \mathrm{RM}$ dynamic leg press force increased in the morning during the first 12 weeks and after completing 24 weeks of training the improvements were independent of the training time and order $(\mathrm{mE}+\mathrm{S}: 13.8 \pm 5.5 \% ; \mathrm{mS}+\mathrm{E}: 16.9 \pm 6.2 \% ; \mathrm{eE}+\mathrm{S}: 18.1 \pm 8.1 \%$; $\mathrm{eS}+\mathrm{E}$ : $19.3 \pm 11.6 \%$, all $\mathrm{p}<0.001$ ) (Table 2). The control group increased maximal dynamic strength performance by $5.1 \pm 5.7 \%(\mathrm{p}<0.05)$, however, all training groups, except $\mathrm{mE}+\mathrm{S}$, increased the morning strength performance significantly more $(p<0.05)$ than controls.

Evening measurements: 1 RM strength increased in the evening in all training groups during the first 12 weeks and by the end of the study all training groups had similarly increased 1 RM $(\mathrm{mE}+\mathrm{S}: \quad 17.5 \pm 7.7 \% ; \mathrm{mS}+\mathrm{E}: 20.7 \pm 9.0 \% ; \mathrm{eE}+\mathrm{S}: 20.5 \pm 8.9 \% ; \mathrm{eS}+\mathrm{E}: 23.6 \pm 12.9 \%$, all $\mathrm{p}<0.001)$ (Table 2). Improvements in all training groups were larger than in the control group $(\mathrm{p}<0.05)$, which showed no significant change in maximal dynamic strength performance in the evening.

\section{Cross sectional area}

All training groups similarly increased CSA of vastus lateralis during the first 12 weeks of training $(\mathrm{mE}+\mathrm{S}: 9.2 \pm 5.6 \% ; \mathrm{mS}+\mathrm{E}: 9.9 \pm 8.3 \%$; eE+S: $14.0 \pm 9.3 \%$; eS+E: $10.0 \pm 6.4 \%$; all $\mathrm{p}<0.05)$ (Figure 2; Table 2). During the second training period (wks 13-24) only eE+S and eS+E groups continued to increase $\mathrm{CSA}(\mathrm{eE}+\mathrm{S}: 5.1 \pm 4.5 \%$; eS+E: $5.1 \pm 4.7 \% ; \mathrm{p}<0.01)$, which led to a 
significant time-of-day main effect $(\mathrm{p}<0.05 ; \mathrm{d}=0.685)$. During weeks $1-24$ all training groups had increased CSA (mE+S: 11.9 $9.2 \%$; mS+E: $12.1 \pm 7.9 \%$; eE+S: $19.8 \pm 10.8 \%$; eS+E: $15.7 \pm 9.1 \%$; all $\mathrm{p}<0.01)$ (Table 2), however a statistical trend for time-of-day main effect was observed in favor of the evening training time $(\mathrm{p}=0.059 ; \mathrm{d}=0.623)$. In the control group CSA remained unchanged.

Only in the eS+E group the individual changes in CSA of vastus lateralis and evening $1 \mathrm{RM}$ dynamic leg press force correlated significantly throughout the 24 weeks of training (week 1-24: $\mathrm{r}=0.638, \mathrm{p}<0.05$; weeks 1-12: $\mathrm{r}=0.657, \mathrm{p}<0.05$; weeks 13-24: $\mathrm{r}=0.579, \mathrm{p}<0.05$ ).

\section{Endurance performance}

Morning measurements: All training groups increased $\mathrm{T}_{\text {exh }}(\mathrm{mE}+\mathrm{S}: 16.2 \pm 5.4 \%$; $\mathrm{mS}+\mathrm{E}$ : $16.1 \pm 12.9 \%$; eE+S: $18.9 \pm 7.5 \%$; eS+E: $11.5 \pm 7.0 \%$; all $\mathrm{p}<0.01)$ in the morning during the first 12 weeks of training independent of the training time and order (Figure 3; Table 2). Only $\mathrm{mE}+\mathrm{S}$ and $\mathrm{eE}+\mathrm{S}$ continued to significantly increase during weeks $13-24(5.5 \pm 3.9 \%$ and $8.1 \pm 5.1 \%$, respectively; $\mathrm{p}<0.001)$. By the end of the study, $\mathrm{T}_{\text {exh }}$ had increased in all of training groups $(\mathrm{mE}+\mathrm{S}: 22.5 \pm 6.4 \%, \mathrm{mS}+\mathrm{E} 21.1 \pm 13.7 \%, \mathrm{eE}+\mathrm{S} 28.3 \pm 7.2 \%$ and $\mathrm{eS}+\mathrm{E} 15.7 \pm 7.5 \% ; \mathrm{p}<0.01)$ and the increases were larger than that observed in the control group ( $<<0.01)$. A statistical main effect for the exercise order $(\mathrm{p}<0.05 ; \mathrm{d}=0.860)$ was found in changes in the morning $\mathrm{T}_{\text {exh }}$ with $\mathrm{mE}+\mathrm{S}$ $(\mathrm{p}=0.051 ; \mathrm{d}=0.982)$ and $\mathrm{eE}+\mathrm{S}(\mathrm{p}<0.001 ; \mathrm{d}=1.711)$ increasing more than $\mathrm{eS}+\mathrm{E}$.

Evening measurements: All training groups increased $\mathrm{T}_{\mathrm{exh}}$ similarly and significantly $(\mathrm{mE}+\mathrm{S}$ :

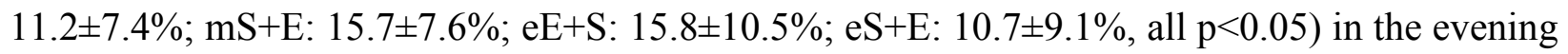
during the first 12 weeks of training (Figure 3; Table 2). During the second 12 weeks the $\mathrm{mS}+\mathrm{E}$ group did not statistically improve $T_{\text {exh }}$, while the significant increases in other training groups 
were larger $(\mathrm{p}<0.05)$ than in $\mathrm{mS}+\mathrm{E}$ during weeks 13-24. A significant main effect for exercise order $(\mathrm{p}<0.05 ; 0.722)$ and time-of-day $(\mathrm{p}<0.05 ; \mathrm{d}=0.493)$ was observed during the second 12 weeks of training in favor of the evening training time and the E+S order. After completing 24 weeks of training all four training groups significantly increased $\mathrm{T}_{\text {exh }}$ in the evening $(\mathrm{mE}+\mathrm{S}$ : $19.7 \pm 6.7 \%$; $\mathrm{mS}+\mathrm{E}: 19.4 \pm 8.5 \%$; eE $+\mathrm{S}: 26.9 \pm 13.0 \%$; eS+E: $18.2 \pm 8.4 \%$, all $\mathrm{p}<0.001$ ), while the increases were statistically larger than in the control group $(\mathrm{p}<0.01)$. A statistical trend for a main effect for exercise order was observed $(p=0.051 ; d=0.617)$ in favor of the $E+S$ groups.

\section{Hormonal concentrations}

Both serum $\mathrm{T}$ and $\mathrm{C}$ concentrations exhibited significant decreases $(\mathrm{p}<0.05)$ from the morning (at 7:30 $\mathrm{h} \pm 30 \mathrm{~min})$ to evening $(18: 30 \mathrm{~h} \pm 30 \mathrm{~min})$ measurements in the beginning $(\mathrm{T}: 10.8$ 26.5\%; C:57.8-73.9\%), after 12 (T: 19.1-359\%; C:64.8-77.4\%) and after 24 weeks of training (T: 24.7-33.9\%; C: $64.5-71.7 \%$ ). No major changes in $\mathrm{T}$ or $\mathrm{C}$ concentrations were observed in the training groups when analyzing each group separately. However, when the morning training groups were combined $(\mathrm{mE}+\mathrm{S}$ and $\mathrm{mS}+\mathrm{E})$, a $17.4 \pm 20.6 \%$ increase was observed in the basal morning $\mathrm{T}$ levels $(\mathrm{p}<0.05)$ and a $16.1 \pm 13.0 \%$ increase in AUC of $\mathrm{T}(\mathrm{p}<0.05)$ after the second training period (wk 13-24) (Figure 4). The combined evening training groups (eE+S and eS+E) showed an increase of $22.7 \pm 29.6 \%$ in basal morning $T$ values $(\mathrm{p}<0.01)$ after the second 12 weeks of training and AUC of T increased after the second 12 weeks of training $(14.1 \pm 17.0 \% ; \mathrm{p}<0.05)$ as well as after the whole 24 weeks $(15.0 \pm 16.7 \% ; \mathrm{p}<0.01)$. When the training groups were combined according to the strength and endurance training order, the combined $\mathrm{E}+\mathrm{S}$ group $(\mathrm{mE}+\mathrm{S}$ and $\mathrm{eE}+\mathrm{S})$ increased AUC of $\mathrm{T}$ by $18.0 \pm 19.0 \%$ after the second training period $(\mathrm{p}<0.01)$ and $12.6 \pm 15.7 \%$ after completing the whole 24 -week training $(\mathrm{p}<0.05)$. The combined $\mathrm{S}+\mathrm{E}$ group $(\mathrm{mS}+\mathrm{E}$ and $\mathrm{eS}+\mathrm{E})$ increased $\mathrm{AUC}$ of $\mathrm{T}$ by $11.0 \pm 11.9 \%$ after the second training period 
$(\mathrm{p}<0.05)$. Basal morning $\mathrm{T}$ concentrations increased similarly in the combined $\mathrm{E}+\mathrm{S}$ and $\mathrm{S}+\mathrm{E}$ groups after the weeks 13-24 (E+S: $17.4 \pm 26.7 \%$; S+E: $23.5 \pm 26.6 \%$; $<<0.01)$ and weeks $1-24$ $(\mathrm{E}+\mathrm{S}: 22.9 \pm 27.9 ; \mathrm{S}+\mathrm{E} 14.4 \pm 22.4 \% ; \mathrm{p}<0.05)$. AUC of $\mathrm{C}$ remained statistically unchanged by the training time and order interaction (Figure 4). In the combined morning group a statistical trend for the increased basal morning $(11.9 \pm 17.7 \%$; $\mathrm{p}<0.06)$ cortisol levels during the weeks $13-24$ was observed. Basal morning C concentrations increased by $14.7 \pm 26.0 \%(\mathrm{p}<0.01)$ in the evening combined group when the changes over the entire 24 weeks of training were analyzed. In the combined $\mathrm{E}+\mathrm{S}$ and $\mathrm{S}+\mathrm{E}$ groups basal morning $\mathrm{C}$ concentrations similarly increased during the weeks 1-24 (E+S: $19.1 \pm 32.2 \%$; S+E: $13.0 \pm 22.3 \%$; $<<0.05)$.

\section{DISCUSSION}

The main results of the present study were that whereas the $\mathrm{S}$ and $\mathrm{E}$ training order and time-ofday of the training did not influence the magnitude of adaptations in maximal dynamic strength performance, the present combined training intervention induced larger gains in muscle crosssectional area in the evening training groups compared to the morning groups, irrespective of the exercise order. Endurance performance development seemed to be related to the sequence of $\mathrm{S}$ and $\mathrm{E}$ training, favoring the $\mathrm{E}+\mathrm{S}$ order both in the morning and in the evening. Furthermore, prolonged combined training may cause training-time-specific adaptations as training in the evening seemed to lead to greater evening endurance performance adaptations compared to the morning training. Diurnal rhythms in testosterone and cortisol remained statistically unaltered by the training order or time. 


\section{Strength performance}

After 24 weeks of time-of-day-specific same-session combined S and E training all training groups similarly increased dynamic $1 \mathrm{RM}$ strength performance. The increases in $1 \mathrm{RM}$ were independent of the training time (morning vs. evening) and order. Some of the previous not-timeof-day-specific combined training studies have suggested that endurance exercise at the beginning of an exercise session may interfere with neural adaptations in young (Eklund et al. 2015) and strength development in old men (Cadore et al. 2013). However, in line with the present results, others have found that gains in maximal strength performance were not related to the sequence of S and E training sessions (Chtara et al. 2008; Schumann et al. 2014). The present results might be specific to the type of endurance training, because the eccentric component of endurance running has been proposed to cause muscle damage (Wilson et al. 2012), whereas cycling has been shown to consist of primarily concentric activity which is biomechanically similar to strength training (Gregor et al. 1991). Consequently, endurance cycling has shown to cause small but statistically significant increases in leg muscle strength in previously untrained men (Häkkinen et al. 2003; Mikkola et al. 2012). It is possible that the cycling activity in the present training program led to synergistic adaptations with strength training, as suggested also by Schumann et al. (2014).

Previous strength training studies have demonstrated that after regular strength training at a particular time-of-day, strength performance increased at the training specific time-of-day (Chtourou et al. 2012, Sedliak et al. 2008). However, similar to our results with combined strength and endurance training, Blonc et al. (2010) showed that strength training displayed no temporal specificity and that training adaptations were not influenced by the time-of-day. The assumption that adaptations to resistance training may vary between different training times is 
based on the fact that various factors influencing maximal strength performance (e.g. body temperature, contractile state of the muscle and/or neural input to the muscle) are highest at a certain time-of-day (Chtourou and Souissi 2012). Therefore, it is possible that lack of diurnal variation in the present maximal dynamic strength performance may have possibly hidden also the diurnal rhythms in maximal strength adaptations. Therefore, future research, where statistically significant diurnal rhythms (morning to evening differences) in maximal dynamic strength performance can be observed, should verify the present results.

\section{Hypertrophy}

In agreement with previous reports, the increase in cross-sectional area of vastus lateralis in the present study was not related to the S and E training order (Cadore et al. 2013; Schumann et al. 2014). It is possible that moderate but repeated force production during cycling action provided an additional stimulus to promote hypertrophy (Mikkola et al. 2012), rather than counteracted with the adaptations elicited by hypertrophic and maximal strength training program. Although some studies have reported the interference with muscle hypertrophy development when the combined S and E training is performed at a high frequency or high intensity (Hickson 1980; Kraemer et al. 1995), no interference by endurance training have been reported when the training frequency remains moderate or low (Häkkinen et al. 2003; McCarthy et al. 2002). Thereby, our study is in agreement that $\mathrm{S}$ and $\mathrm{E}$ training (as cycling) order does not influence the magnitude of adaptations in muscle CSA, especially when the combined training frequency does not exceed 23/week.

In the present study all training groups similarly and significantly increased CSA of vastus lateralis during the first 12 weeks. However, a significant main effect for the training time-of-day 
was found for the changes in CSA of vastus lateralis after the second 12 weeks of combined training, showing that groups training in the evening hours increased CSA significantly more compared to groups training in the morning. Sedliak et al. (2009) have shown that time-of-dayspecific strength training for 2-3 months in the morning and afternoon hours is similarly effective when aiming for muscle hypertrophy. However, the increase in mid-thigh muscle volume, although minor and statistically insignificant, favored the afternoon strength training group (Sedliak et al. 2009). Our results are similar with those of Sedliak et al. (2009) for the first training period (3 months), demonstrating that training time of combined strength and endurance training did not significantly influence the magnitude of adaptations in muscle mass. However, when the training period is prolonged (6 months), the evening training time of combined strength and endurance training may be more beneficial for muscle hypertrophy development. In the present study, training programs were carefully matched for all training groups for training frequencies, intensities and duration and therefore, differences in muscle mass gains might be explained by the training time. In addition, Sedliak et al. (2013) have suggested that strength training in the morning may not provide optimal stimulus for some individuals because of large inter-individual variability in protein signaling after morning compared to the evening strength training. In addition, the significant correlations observed between individual changes in CSA of vastus lateralis and strength of the lower extremities demonstrated that only in the eS+E group the individuals who experienced larger gains in muscle mass also increased more their trainingtime-specific (evening) strength performance. However, it is possible that the present study was underpowered when all four training groups were analyzed separately. Consequently, it is possible that small sample size may have led to insufficient power and type 2 error. Although the 
present study suggests that regular combined S and E training in the evening hours may be more optimal for muscle hypertrophy, further research is needed to confirm our results.

\section{Endurance performance}

Time to exhaustion improved in all training groups over the 24 -week training period. After the first 12 weeks the increases were similar in all training groups, however, a significant order main effect was observed in favor of the $\mathrm{E}+\mathrm{S}$ order after the second training period both in the morning and in the evening. Several studies have shown that the $\mathrm{S}$ and $\mathrm{E}$ training order does not influence the magnitude of adaptations in endurance performance (Cadore et al. 2013; Chtara et al. 2008; Schumann et al. 2014) or that combined training limited the increase in $\mathrm{VO}_{2}$ max when women performed E before S training (Gravelle and Blessing 2000). However, similar to our present results, Chtara et al. (2005) also found larger improvements in endurance performance when E training preceded S training. Although Dolezal and Potteiger (1998) and Nelson et al. (1990) did not compare different exercise order groups, they did indicate that their combined group that always performed $\mathrm{S}$ training first showed disrupted aerobic development. In concordance with our current findings, Nelson et al. (1990) also noted suppressed adaptation in endurance performance only during the second half of a 20 -week training program. Given that the strength loading has been shown to impair muscle force generation capacity (Schumann et al. 2013), S training in close proximity with E training may cause difficulty in optimizing physiological adaptations to E training (Chtara et al. 2005). The E training intensity might be one factor to explain why some studies have not found any order effect in endurance performance adaptations. In the previous study by our team (Schumann et al. 2014) a similar E training program as in the present study was used, however, a smaller amount of high intensity interval training sessions were included in the earlier intervention. In addition, the main effect for 
exercise order was observed after completing the second training period during which both training intensity and frequency were increased. Possibly the increased training intensity, the larger amount of interval training sessions as well as increased training frequency during the second training period may have led to suppressed endurance performance adaptations in the groups who started with S training.

In general, the literature concerning time-of-day effects on endurance performance yields to somewhat inconclusive results (Bessot et al. 2006; Deschenes et al. 1998). Similar to the present study, Deschenes et al. (1998) have suggested that maximal aerobic performance remains constant throughout the day, despite the fact that certain important physiological parameters are subject to diurnal variation. The present results of time-of-day-specific adaptations from the morning measurements are in accordance with Hill et al. (1989) suggesting that the magnitude of the endurance training induced increases in maximal endurance performance were not related to the training time. However, the endurance performance improvements in the evening seemed to be influenced by training time during the latter 12 weeks of training, as evening training seemed to lead to greater increases in time to exhaustion compared to morning training. This suggests that a prolonged training period might be necessary to be able to observe training-time-specific adaptations during combined $\mathrm{S}$ and $\mathrm{E}$ training.

\section{Diurnal variation in serum testosterone and cortisol}

In the present study both total serum $\mathrm{T}$ and $\mathrm{C}$ exhibited significant diurnal rhythms in all five groups well in line with previous studies (e.g. Kraemer et al. 2001). Neither the morning nor the evening combined training programs led to any systematic changes in typical diurnal variations in resting serum total $\mathrm{T}$ and $\mathrm{C}$ concentrations. Limited results of acute hormonal response studies 
have shown temporary phase shifting effects of strength (Nindl et al. 2001) and endurance (Buxton et al. 2003) exercise. However, others have suggested that heavy resistance exercise has no significant effect on the circadian rhythm of salivary testosterone in previously strengthtrained men (Häkkinen et al. 1988; Kraemer et al. 2001). Therefore, the influences of short-term training protocols seem to be insufficient to alter the circadian profile of $\mathrm{T}$ and $\mathrm{C}$ (Teo et al. 2011). Sedliak et al. (2007) showed that several weeks of strength training in the morning hours may decrease the resting $\mathrm{C}$ concentrations, whereas the evening training did not have that effect. In the same study, no significant changes were observed in resting $T$ concentrations (Sedliak et al. 2007). The authors also proposed that the changes in C concentrations may have occurred due to the decreased anticipatory psychological stress prior to the morning testing (Sedliak et al. 2007). No previous studies appear to have dealt with possible phase shifting properties of prolonged combined $\mathrm{S}$ and $\mathrm{E}$ training on hormonal rhythms. However, the low sampling frequency may have precluded our ability to evaluate the possible training-induced phase shifts properly (Sedliak et al. 2007). In addition, although the overall training volume was large (2-3 E sessions and 2-3 S sessions per week) for previously untrained men, the training frequency of 2-3 double sessions (2-3 E+S or $\mathrm{S}+\mathrm{E}$ sessions) allowed for at least 48 hours of recovery which may have provided sufficient time for photic and social contact factors (Duffy et al. 1996) to reset any possible phase-shifting effect caused by the exercise training. Although, increased morning basal serum $\mathrm{T}$ and $\mathrm{C}$ concentrations were observed after regular combined $\mathrm{S}$ and $\mathrm{E}$ training for 24 weeks, these changes did not seem to be related to the training order or the training time. It is possible that increases in $\mathrm{T}$ and $\mathrm{C}$ concentrations were caused by the seasonal variation due to sampling at different times of the year (Andersson et al. 2003; Persson et al. 2008). Therefore, it 
remains to be examined whether exercise can exert a sufficiently strong influence to alter the circadian rhythm of $\mathrm{T}$ and $\mathrm{C}$.

\section{Conclusions}

This study showed that whereas no major between-group differences were observed over the first 12 weeks, the strength and endurance training order and time-of-day of the training may be important factors to optimize the magnitude of adaptations to combined strength and endurance training, when the training period is extended beyond 12 weeks. The present combined training program in the evening led to larger gains in muscle mass compared to the same training program in the morning hours. The mechanisms for these dissimilar gains after morning and evening combined training, however, are unclear. The improvements in strength performance did not seem to be related to the strength and endurance training time or order, while performing strength training regularly before an endurance session may interfere with the quality of the endurance training adaptations. Therefore, when improvements in endurance performance are sought, it is advisable to perform an endurance session before a strength training session preferably at the time-of-day when the improvements are desired, if the training period is prolonged. To improve strength performance, strength and endurance training sessions can be performed in the desired order in the morning or evening based on the personal preferences. However, gains in muscle mass might be larger, when regularly performing combined strength and endurance training in the evening.

Conflict of interest: The authors state that there is no conflict of interest. 
Acknowledgements: Gratitude is expressed to the Finnish Ministry of Education and Culture and to the Estonian Ministry of Education and Research (SA Archimedes) for financially supporting the completion of this research and to the dedicated group of participants. 


\section{REFERENCES}

Ahtiainen, J.P., Hoffren, M., Hulmi, J.J., Pietikäinen, M., Mero, A.A., Avela, J., et al. 2010. Panoramic ultrasonography is a valid method to measure changes in skeletal muscle crosssectional area. Eur. J. Appl. Physiol. 108(2): 273-9. doi: 10.1007/s00421-009-1211-6.

Ahtiainen, J.P., Pakarinen, A., Alen, M., Kraemer, W.J., and Häkkinen, K. 2003. Muscle hypertrophy, hormonal adaptations and strength development during strength training in strength-trained and untrained men. Eur. J. Appl. Physiol. 89(6): 555-63. doi: 10.1007/s00421-003-0833-3.

Andersson, A.-M., Carlsen, E., Petersen, J.H., and Skakkebaek, N.E. 2003. Variation in levels of serum inhibin B, testosterone, estradiol, luteinizing hormone, follicle-stimulating hormone, and sex hormone-binding globulin in monthly samples from healthy men during a 17-month period: possible effects of seasons. J. Clin. Endocrinol. Metab. 88(2): 932-7. doi: 10.1210/jc.2002-020838.

Bessot, N., Nicolas, A., Moussay, S., Gauthier, A., Sesboüé, B., and Davenne, D. 2006. The effect of pedal rate and time of day on the time to exhaustion from high-intensity exercise. Chronobiol. Int. 23(5): 1009-24. doi: 10.1080/07420520600920726.

Blonc, S., Perrot, S., Racinais, S., Aussepe, S., and Hue, O. 2010. Effects of 5 weeks of training at the same time of day on the diurnal variations of maximal muscle power performance. $\mathrm{J}$. Strength Cond. Res. 24(1): 23-9. doi: 10.1519/JSC.0b013e3181b295d6.

Buxton, O.M., Lee, C.W., L’Hermite-Baleriaux, M., Turek, F.W., and Van Cauter, E. 2003. Exercise elicits phase shifts and acute alterations of melatonin that vary with circadian phase. Am. J. Physiol. Regul. Integr. Comp. Physiol. 284(3): R714-24. doi: 
10.1152/ajpregu.00355.2002.

Cadore, E.L., Izquierdo, M., Pinto, S.S., Alberton, C.L., Pinto, R.S., Baroni, B.M., et al. 2013. Neuromuscular adaptations to concurrent training in the elderly: Effects of intrasession exercise sequence. Age (Omaha). 35(3): 891-903. doi: 10.1007/s11357-012-9405-y.

Chtara, M., Chamari, K., Chaouachi, M., Chaouachi, A., Koubaa, D., Feki, Y., et al. 2005. Effects of intra-session concurrent endurance and strength training sequence on aerobic performance and capacity. Br. J. Sports Med. 39(8): 555-560. doi: 10.1136/bjsm.2004.015248.

Chtara, M., Chaouachi, A., Levin, G.T., Chaouachi, M., Chamari, K., Amri, M., et al. 2008. Effect of concurrent endurance and circuit resistance training sequence on muscular strength and power development. J. Strength Cond. Res. 22(4): 1037-1045. doi: 10.1519/JSC.0b013e31816a4419.

Chtourou, H., Driss, T., Souissi, S., Gam, A., Chaouachi, A., and Souissi, N. 2012. The effect of strength training at the same time of the day on the diurnal fluctuations of muscular anaerobic performances. J. Strength Cond. Res. 26(1): 217-25. doi: 10.1519/JSC.0b013e31821d5e8d.

Chtourou, H., Hammouda, O., Aloui, A., Chaabouni, K., Makni-Ayedi, F., Wahl, M., et al. 2013. The effect of time of day on hormonal responses to resistance exercise. Biol. Rhythm Res. 45(2): 247-256. Taylor \& Francis. doi: 10.1080/09291016.2013.805909.

Chtourou, H., and Souissi, N. 2012. The effect of training at a specific time of day: a review. J. Strength Cond. Res. 26: 1984-2005. doi: 10.1519/JSC.0b013e31825770a7.

Deschenes, M.R., Sharma, J. V, Brittingham, K.T., Casa, D.J., Armstrong, L.E., and Maresh, 
C.M. 1998. Chronobiological effects on exercise performance and selected physiological responses. Eur. J. Appl. Physiol. Occup. Physiol. 77(3): 249-56. doi: $10.1007 / \mathrm{s} 004210050329$.

Dolezal, B.A., and Potteiger, J.A. 1998. Concurrent resistance and endurance training influence basal metabolic rate in nondieting individuals. J. Appl. Physiol. 85(2): 695-700. Available from http://www.ncbi.nlm.nih.gov/pubmed/9688748 [accessed 6 November 2015].

Duffy, J.F., Kronauer, R.E., and Czeisler, C.A. 1996. Phase-shifting human circadian rhythms: influence of sleep timing, social contact and light exposure. J. Physiol. 495 ( Pt 1: 289-97. Available from http://www.pubmedcentral.nih.gov/articlerender.fcgi?artid=1160744\&tool=pmcentrez\&ren dertype=abstract [accessed 5 November 2015].

Eklund, D., Pulverenti, T., Bankers, S., Avela, J., Newton, R., Schumann, M., et al. 2015. Neuromuscular Adaptations to Different Modes of Combined Strength and Endurance Training. Int. J. Sports Med. 36(2): 120-9. doi: 10.1055/s-0034-1385883.

Fyfe, J.J., Bishop, D.J., and Stepto, N.K. 2014. Interference between concurrent resistance and endurance exercise: molecular bases and the role of individual training variables. Sports Med. 44(6): 743-62. doi: 10.1007/s40279-014-0162-1.

Gravelle, B.L., and Blessing, D.L. 2000. Physiological Adaptation in Women Concurrently Training for Strength and Endurance. doi: 10.1519/15334287(2000)014<0005:PAIWCT>2.0.CO;2.

Gregor, R.J., Broker, J.P., and Ryan, M.M. 1991. The biomechanics of cycling. Exerc. Sport Sci. Rev. 19: 127-69. Available from http://www.ncbi.nlm.nih.gov/pubmed/1936084 [accessed 
6 November 2015].

Hackney, A.C., Szczepanowska, E., and Viru, A.M. 2003. Basal testicular testosterone production in endurance-trained men is suppressed. Eur. J. Appl. Physiol. 89(2): 198-201. doi: 10.1007/s00421-003-0794-6.

Hickson, R.C. 1980. Interference of strength development by simultaneously training for strength and endurance. Eur. J. Appl. Physiol. Occup. Physiol. 45(2-3): 255-263. doi: 10.1007/BF00421333.

Hill, D.W., Cureton, K.J., and Collins, M.A. 1989. Circadian specificity in exercise training. Ergonomics 32(1): 79-92. doi: 10.1080/00140138908966069.

Hill, D.W., Leiferman, J.A., Lynch, N.A., Dangelmaier, B.S., and Burt, S.E. 1998. Temporal specificity in adaptations to high-intensity exercise training. Med. Sci. Sports Exerc. 30(3): 450-5. Available from http://www.ncbi.nlm.nih.gov/pubmed/9526893 [accessed 5 November 2015].

Häkkinen, K., Alen, M., Kraemer, W.J., Gorostiaga, E., Izquierdo, M., Rusko, H., et al. 2003. Neuromuscular adaptations during concurrent strength and endurance training versus strength training. Eur. J. Appl. Physiol. 89(1): 42-52. doi: 10.1007/s00421-002-0751-9.

Häkkinen, K., Pakarinen, A., Alén, M., Kauhanen, H., and Komi, P. V. 1988. Daily hormonal and neuromuscular responses to intensive strength training in 1 week. Int. J. Sports Med. 9: 422-428. doi: 10.1055/s-2007-1025044.

Häkkinen, K., Pakarinen, A., Alén, M., and Komi, P. V. 1985. Serum hormones during prolonged training of neuromuscular performance. Eur. J. Appl. Physiol. Occup. Physiol. 53(4): 287-93. Available from http://www.ncbi.nlm.nih.gov/pubmed/4039254 [accessed 5 
November 2015].

Kraemer, W.J., Loebel, C.C., Volek, J.S., Ratamess, N.A., Newton, R.U., Wickham, R.B., et al. 2001. The effect of heavy resistance exercise on the circadian rhythm of salivary testosterone in men. Eur. J. Appl. Physiol. 84(1-2): 13-8. doi: 10.1007/s004210000322.

Kraemer, W.J., Patton, J.F., Gordon, S.E., Harman, E.A., Deschenes, M.R., Reynolds, K., et al. 1995. Compatibility of high-intensity strength and endurance training on hormonal and skeletal muscle adaptations. J. Appl. Physiol. 78(3): 976-89. Available from http://www.ncbi.nlm.nih.gov/pubmed/7775344 [accessed 14 September 2015].

Kraemer, W.J., and Ratamess, N.A. 2005. Hormonal responses and adaptations to resistance exercise and training. Sports Med. 35(4): 339-61. Available from http://www.ncbi.nlm.nih.gov/pubmed/15831061 [accessed 1 November 2015].

Leveritt, M., and Abernethy, P.J. 1999. Acute Effects of High-Intensity Endurance Exercise on Subsequent Resistance Activity. doi: 10.1519/15334287(1999)013<0047:AEOHIE $>2.0 . \mathrm{CO} ; 2$.

McCarthy, J.P., Pozniak, M.A., and Agre, J.C. 2002. Neuromuscular adaptations to concurrent strength and endurance training. Med. Sci. Sports Exerc. 34(3): 511-9. Available from http://www.ncbi.nlm.nih.gov/pubmed/11880817 [accessed 28 September 2015].

Mikkola, J., Rusko, H., Izquierdo, M., Gorostiaga, E.M., and Häkkinen, K. 2012. Neuromuscular and cardiovascular adaptations during concurrent strength and endurance training in untrained men. Int. J. Sports Med. 33(9): 702-10. doi: 10.1055/s-0031-1295475.

Nelson, A.G., Arnall, D.A., Loy, S.F., Silvester, L.J., and Conlee, R.K. 1990. Consequences of combining strength and endurance training regimens. Phys. Ther. 70(5): 287-294. doi: 


\subsection{9/00126548-200008000-00011.}

Nindl, B.C., Kraemer, W.J., Deaver, D.R., Peters, J.L., Marx, J.O., Heckman, J.T., et al. 2001. LH secretion and testosterone concentrations are blunted after resistance exercise in men. J. Appl. Physiol. 91(3): 1251-8. Available from http://www.ncbi.nlm.nih.gov/pubmed/11509523 [accessed 6 November 2015].

Persson, R., Garde, A.H., Hansen, A.M., Osterberg, K., Larsson, B., Orbaek, P., et al. 2008. Seasonal variation in human salivary cortisol concentration. Chronobiol. Int. 25(6): 923-37. doi: $10.1080 / 07420520802553648$.

Roenneberg, T., Wirz-Justice, A., and Merrow, M. 2003. Life between clocks: daily temporal patterns of human chronotypes. J. Biol. Rhythms 18: 80-90. doi: $10.1177 / 0748730402239679$.

Schumann, M., Eklund, D., Taipale, R.S., Nyman, K., Kraemer, W.J., Häkkinen, A., et al. 2013. Acute neuromuscular and endocrine responses and recovery to single-session combined endurance and strength loadings: "order effect" in untrained young men. J. Strength Cond. Res. 27(2): 421-33. doi: 10.1519/JSC.0b013e31827f4a10.

Schumann, M., Küüsmaa, M., Newton, R.U., Sirparanta, A.-I., Syväoja, H., Häkkinen, A., et al. 2014. Fitness and Lean Mass Increases during Combined Training Independent of Loading Order. Med. Sci. Sport. Exerc. 46(9): 1758-1768. doi: 10.1249/MSS.0000000000000303.

Sedliak, M., Finni, T., Cheng, S., Kraemer, W.J., and Häkkinen, K. 2007. Effect of time-of-dayspecific strength training on serum hormone concentrations and isometric strength in men. Chronobiol. Int. 24(6): 1159-77. doi: 10.1080/07420520701800686.

Sedliak, M., Finni, T., Cheng, S., Lind, M., and Häkkinen, K. 2009. Effect of time-of-day- 
specific strength training on muscular hypertrophy in men. J. Strength Cond. Res. 23(9): 2451-7. doi: 10.1519/JSC.0b013e3181bb7388.

Sedliak, M., Finni, T., Peltonen, J., and Häkkinen, K. 2008. Effect of time-of-day-specific strength training on maximum strength and EMG activity of the leg extensors in men. J. Sports Sci. 26: 1005-1014. doi: 10.1080/02640410801930150.

Sedliak, M., Zeman, M., Buzgó, G., Cvečka, J., Hamar, D., Laczo, E., et al. 2013. Effects of time of day on resistance exercise-induced anabolic signaling in skeletal muscle. Biol. Rhythm Res. 44(5): 756-770. Taylor \& Francis. doi: 10.1080/09291016.2012.740314.

Souissi, N., Gauthier, A., Sesboüé, B., Larue, J., and Davenne, D. 2002. Effects of regular training at the same time of day on diurnal fluctuations in muscular performance. J. Sports Sci. 20(11): 929-37. doi: 10.1080/026404102320761813.

Teo, W., Newton, M.J., and McGuigan, M.R. 2011. Circadian rhythms in exercise performance: Implications for hormonal and muscular adaptation. J. Sport. Sci. Med. 10: 600-606.

Torii, J., Shinkai, S., Hino, S., Kurokawa, Y., Tomita, N., Hirose, M., et al. 1992. Effect of time of day on adaptive response to a 4-week aerobic exercise program. J. Sports Med. Phys. Fitness 32(4): 348-52. Available from http://www.ncbi.nlm.nih.gov/pubmed/1293416 [accessed 5 November 2015].

West, D.W.D., and Phillips, S.M. 2012. Associations of exercise-induced hormone profiles and gains in strength and hypertrophy in a large cohort after weight training. Eur. J. Appl. Physiol. 112(7): 2693-2702. doi: 10.1007/s00421-011-2246-z.

Wilson, J.M., Marin, P.J., Rhea, M.R., Wilson, S.M.C., Loenneke, J.P., and Anderson, J.C. 2012. Concurrent training: a meta-analysis examining interference of aerobic and resistance 


\section{Page 32 of 40}

exercises. J. Strength Cond. Res. 26(8): 2293-307. doi: 10.1519/JSC.0b013e31823a3e2d. 


\section{Page 33 of 40}

Tables

Table 1. Basal anthropometric characteristics \pm SD of the participants.

\begin{tabular}{lcccc}
\hline & Age $(\mathrm{yrs}) \pm \mathrm{SD}$ & Height $(\mathrm{m}) \pm \mathrm{SD}$ & Weight $(\mathrm{kg}) \pm \mathrm{SD}$ & $\mathrm{BMI}\left(\mathrm{kg} / \mathrm{m}^{2}\right) \pm \mathrm{SD}$ \\
\hline $\mathrm{mE}+\mathrm{S}(\mathrm{n}=9)$ & $36.1 \pm 6.5$ & $1.80 \pm 0.04$ & $86.1 \pm 8.9$ & $26.5 \pm 2.1$ \\
$\mathrm{mS}+\mathrm{E}(\mathrm{n}=9)$ & $30.8 \pm 5.0$ & $1.82 \pm 0.08$ & $82.0 \pm 14.0$ & $24.8 \pm 3.8$ \\
$\mathrm{eE}+\mathrm{S}(\mathrm{n}=12)$ & $31.4 \pm 4.6$ & $1.80 \pm 0.07$ & $78.0 \pm 8.5$ & $24.1 \pm 2.5$ \\
$\mathrm{eS}+\mathrm{E}(\mathrm{n}=12)$ & $31.4 \pm 6.5$ & $1.81 \pm 0.06$ & $80.0 \pm 10.6$ & $24.5 \pm 2.7$ \\
Controls $(\mathrm{n}=10)$ & $32.4 \pm 4.9$ & $1.81 \pm 0.08$ & $79.0 \pm 12.8$ & $23.9 \pm 2.7$ \\
\hline
\end{tabular}

$\mathrm{m}=$ training in the morning; $\mathrm{e}=$ training in the evening; $\mathrm{E}+\mathrm{S}=$ endurance before strength training; $\mathrm{S}+\mathrm{E}=$ strength before endurance. 
Table 2. Absolute values \pm SD of 1 repetition maximal (1RM) strength in leg press, time to exhaustion and muscle cross-sectional area of $\mathrm{m}$. vastus lateralis at pre-, mid-and post measurements in the morning and in the evening.

\begin{tabular}{|c|c|c|c|c|c|c|}
\hline & \multicolumn{2}{|c|}{ Pre-measurements } & \multicolumn{2}{|c|}{ Mid-measurements } & \multicolumn{2}{|c|}{ Post-measurements } \\
\hline & Morning & Evening & Morning & Evening & Morning & Evening \\
\hline \multicolumn{7}{|l|}{$1 \mathrm{RM}(\mathrm{kg}) \pm \mathrm{SD}$} \\
\hline$m E+S(n=9)$ & $161.8 \pm 20.4$ & $158.3 \pm 21.4$ & $178.3 \pm 20.5$ & $180.6 \pm 17.8$ & $183.5 \pm 18.7$ & $185.0 \pm 19.7$ \\
\hline$m S+E(n=9)$ & $149.1 \pm 22.3$ & $146.6 \pm 24.6$ & $170.0 \pm 27.5$ & $170.5 \pm 29.3$ & $174.2 \pm 26.8$ & $176.7 \pm 30.8$ \\
\hline$e E+S(n=12)$ & $142.6 \pm 24.7$ & $140.4 \pm 25.6$ & $163.0 \pm 21.7$ & $161.6 \pm 21.6$ & $166.8 \pm 19.5$ & $167.4 \pm 20.0$ \\
\hline$e S+E(n=12)$ & $141.4 \pm 26.0$ & $136.9 \pm 26.2$ & $160.1 \pm 25.1$ & $161.7 \pm 24.8$ & $166.6 \pm 21.3$ & $166.8 \pm 21.5$ \\
\hline Controls $(n=10)$ & $142.1 \pm 25.9$ & $144.2 \pm 23.2$ & $149.4 \pm 25.1$ & $151.0 \pm 26.3$ & $148.6 \pm 23.7$ & $148.5 \pm 23.6$ \\
\hline \multicolumn{7}{|c|}{ Time to exhaustion (min:sec) \pm SD } \\
\hline$m E+S(n=9)$ & $18: 20 \pm 02: 17$ & $18: 47 \pm 02: 50$ & $21: 16 \pm 03: 25$ & $20: 49 \pm 02: 55$ & $22: 23 \pm 03: 21$ & $22: 25 \pm 03: 21$ \\
\hline$m S+E(n=9)$ & $17: 20 \pm 03: 20$ & $17: 28 \pm 02: 59$ & $19: 47 \pm 02: 18$ & $20: 02 \pm 02: 51$ & $20: 39 \pm 02: 09$ & $20: 37 \pm 02: 26$ \\
\hline$e E+S(n=12)$ & $16: 44 \pm 02: 23$ & $16: 57 \pm 02: 35$ & $19: 48 \pm 02: 23$ & $19: 38 \pm 02: 51$ & $21: 20 \pm 02: 25$ & $21: 36 \pm 02: 24$ \\
\hline$e S+E(n=12)$ & $18: 22 \pm 03: 39$ & $18: 32 \pm 03: 45$ & $20: 13 \pm 03: 01$ & $20: 08 \pm 02: 51$ & $21: 03 \pm 03: 36$ & $21: 34 \pm 03: 00$ \\
\hline Controls $(n=10)$ & $19: 19 \pm 02: 48$ & $19: 37 \pm 03: 14$ & $19: 53 \pm 02: 34$ & $19: 50 \pm 02: 45$ & $19: 47 \pm 02: 43$ & $20: 08 \pm 02: 31$ \\
\hline \multicolumn{7}{|c|}{ Cross-sectional area $\left(\mathrm{cm}^{2}\right) \pm S D$} \\
\hline$m E+S(n=9)$ & $24.56 \pm 3.16$ & - & $26.77 \pm 3.25$ & - & $27.38 \pm 3.34$ & - \\
\hline$m S+E(n=9)$ & $20.79 \pm 2.51$ & - & $22.80 \pm 2.56$ & - & $23.24 \pm 2.33$ & - \\
\hline$e E+S(n=12)$ & $21.22 \pm 4.94$ & - & $23.94 \pm 4.76$ & - & $25.15 \pm 4.86$ & - \\
\hline$e S+E(n=12)$ & $21.75 \pm 3.43$ & - & $23.88 \pm 3.76$ & - & $25.05 \pm 3.76$ & - \\
\hline Controls $(n=10)$ & $21.38 \pm 3.32$ & - & $21.82 \pm 3.81$ & - & $21.79 \pm 3.46$ & - \\
\hline
\end{tabular}




\section{Page 35 of 40}

Table 3. Summary of the strength training program for lower extremities.

\begin{tabular}{lcccccc}
\hline & \multicolumn{3}{c}{ Training weeks 1-12 } & \multicolumn{3}{c}{ Training weeks 13-24 } \\
\hline \multicolumn{1}{c}{ Week } & $1-4$ & $5-8$ & $9-12$ & $13-14$ & $15-20$ & $21-24$ \\
\hline Training type & Circuit & Hypertrophic & Maximal & Circuit & Hypertrophic & Maximal \\
Intensity (\% of 1 RM) & $40-70$ & $70-85$ & $75-95$ & $50-75$ & $75-85$ & $80-95$ \\
Sets & $2-3$ & $3-4$ & $3-5$ & $3-4$ & $3-4$ & $3-5$ \\
Repetitions & $10-20$ & $10-15$ & $3-8$ & $10-15$ & $10-15$ & $3-8$ \\
Rest (min) & no & $1.5-2$ & $2-3$ & no & $1-5-2$ & $2-3$ \\
\hline
\end{tabular}




\section{Figure legend}

Figure 1. Study design and measurements. $1 \mathrm{RM}=$ one repetition maximum in the dynamic leg press; $\mathrm{T}_{\mathrm{exh}}=$ time to exhaustion during the incremental cycling test; $\mathrm{CSA}=$ cross sectional area; $\mathrm{m}=$ morning; $\mathrm{e}=$ evening

Figure 2. Changes in vastus lateralis cross-sectional area after 12 and 24 weeks of combined training; *sign. $(\mathrm{p}<0.05)$ within-group increase; \# sign. different from controls; \& sign. time-of-day main (TOD) effect. Detailed levels of significance are presented in the results section. $\mathrm{m}=$ morning; $\mathrm{e}=$ evening; $\mathrm{E}+\mathrm{S}=$ endurance before strength; $\mathrm{S}+\mathrm{E}=$ strength before endurance

Figure 3. Changes in time to exhaustion $\left(\mathrm{T}_{\mathrm{exh}}\right)$ in the morning $(\mathrm{A})$ and in the evening $(\mathrm{B})$ after 12 and 24 weeks of combined training; *sign. $(\mathrm{p}<0.05)$ within-group increase; $a$ sign. betweengroup differences as indicated; \# sign. different from controls; \$ sign. order main effect; \& sign. time-of-day (TOD) main effect. Detailed levels of significance are presented in the results section; $\mathrm{m}=$ morning; $\mathrm{e}=$ evening; $\mathrm{E}+\mathrm{S}=$ endurance before strength; $\mathrm{S}+\mathrm{E}=$ strength before endurance

Figure 4. Diurnal variations in serum testosterone and cortisol concentrations at pre-, mid- and post-measurements in the combined morning group (A) and combined evening group (B). *sign. $(\mathrm{p}<0.05)$ within-group change from wk 0 to wk 12 ; $\$$ sign. within-group change from wk 12 to wk 24; a sign. within-group change from wk 0 to wk 24. Detailed levels of significance are presented in the results section 


\begin{tabular}{|c|c|c|c|c|c|c|c|c|c|}
\hline \multicolumn{2}{|c|}{ Pre-measurements } & & & Mid-measurements & nts & & \multicolumn{3}{|c|}{ Post-measurements } \\
\hline & \multicolumn{4}{|c|}{$\begin{array}{c}\text { Combined training } \\
\text { wks 1-12 }\end{array}$} & \multicolumn{3}{|c|}{$\begin{array}{c}\text { Combined training } \\
\text { wks 13-24 }\end{array}$} & & \\
\hline \multicolumn{10}{|c|}{ Measurements } \\
\hline $\begin{array}{c}\text { Venous blood samples } \\
\text { (drawn during one day) } \\
\text { 7:30 } \mathrm{h} \pm 30 \mathrm{~min} \\
\text { 9:30 } \mathrm{h} \pm 30 \mathrm{~min} \\
\text { 16:30 } \mathrm{h} \pm 30 \mathrm{~min} \\
\text { 18:30 } \mathrm{h} \pm 30 \mathrm{~min}\end{array}$ & $\stackrel{\geq 36 h}{\longleftrightarrow}$ & $\begin{array}{l}\text { Strength } \\
\text { measurement } \\
1 \text { RM } \\
\text { in the morning or } \\
\text { evening) }\end{array}$ & $\stackrel{236 h}{\longleftrightarrow}$ & $\begin{array}{c}\text { Strength } \stackrel{\geq 36 h}{\longleftrightarrow} \\
\text { measurement } \\
1 \text { RM } \\
\text { (in the evening or } \\
\text { morning) }\end{array}$ & $\begin{array}{l}\text { Incremental } \\
\text { cycling test } \\
\mathrm{T}_{\text {exh }} \\
\text { (in the monring or } \\
\text { evening) }\end{array}$ & $\stackrel{236 h}{\longleftrightarrow}$ & $\begin{array}{l}\text { Incremental } \\
\text { cycling test } \\
T_{\text {exh }} \\
\text { in the evening or } \\
\text { morning) }\end{array}$ & $\stackrel{236 h}{\longleftrightarrow}$ & $\begin{array}{l}\text { Ultrasound } \\
\text { CSA of } \\
\text { vastus lateralis }\end{array}$ \\
\hline
\end{tabular}

Figure 1. 


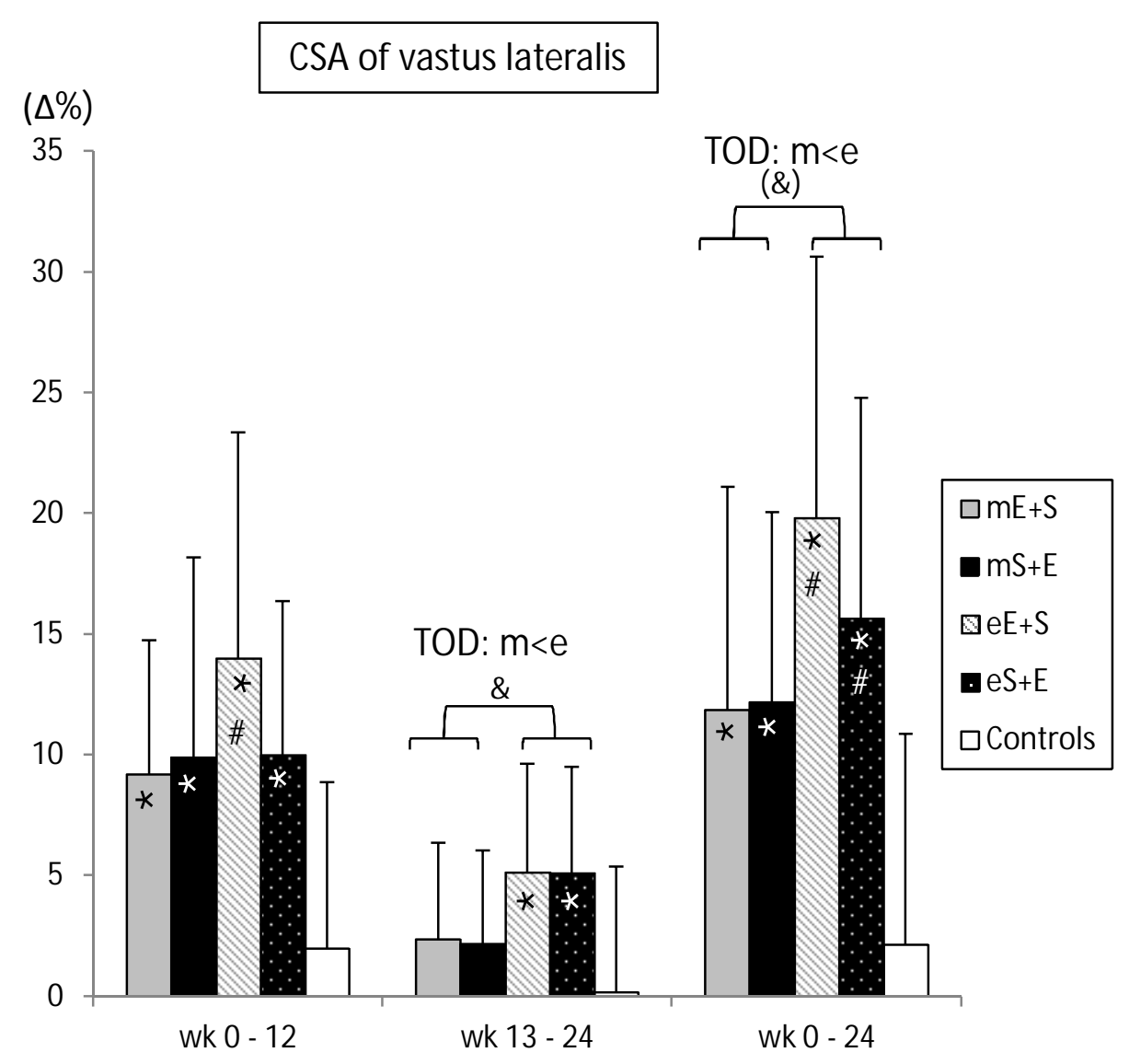

Figure 2. 
B) $T_{\text {exh }}$ in the evening

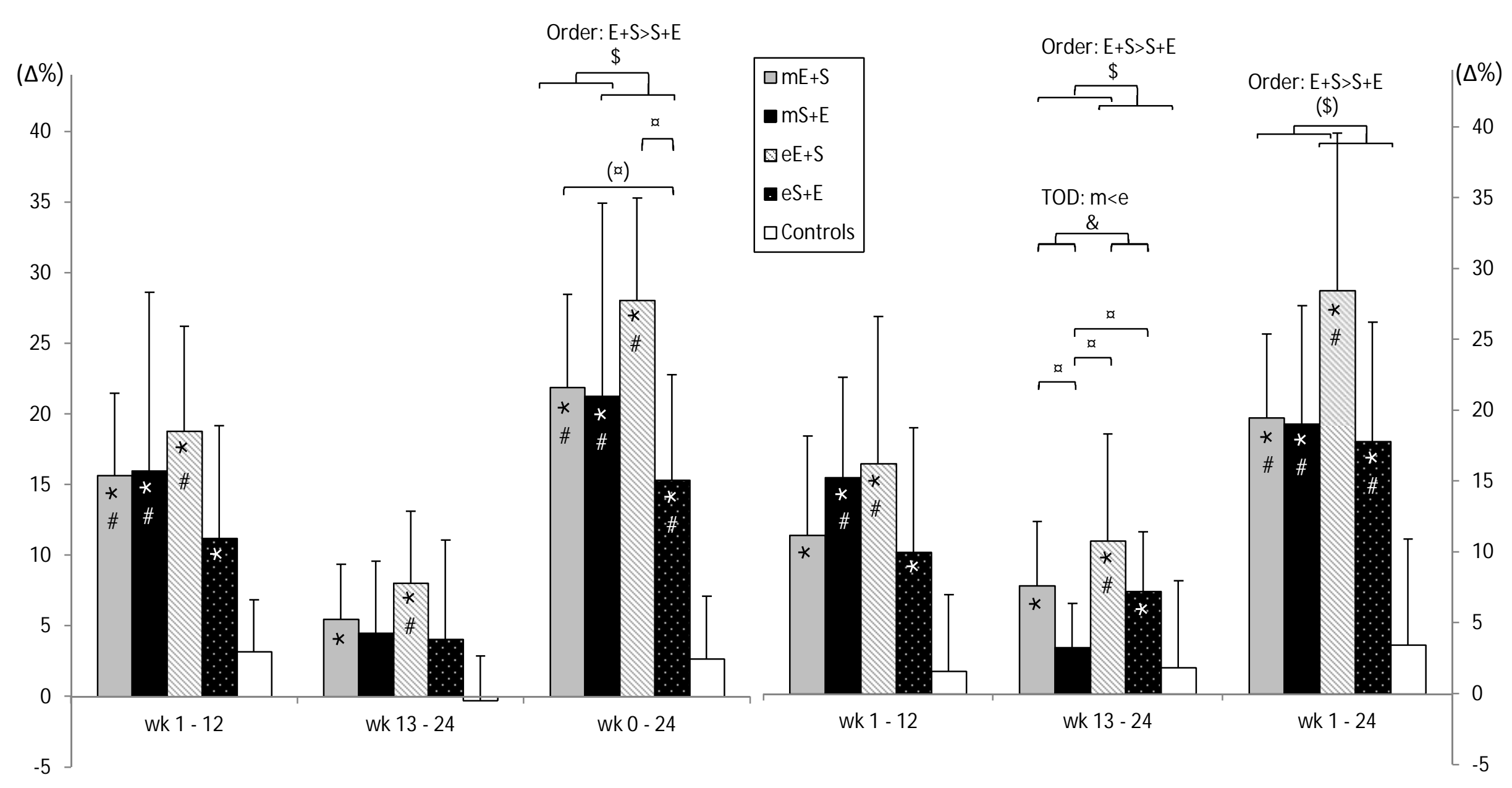

Figure 3. 

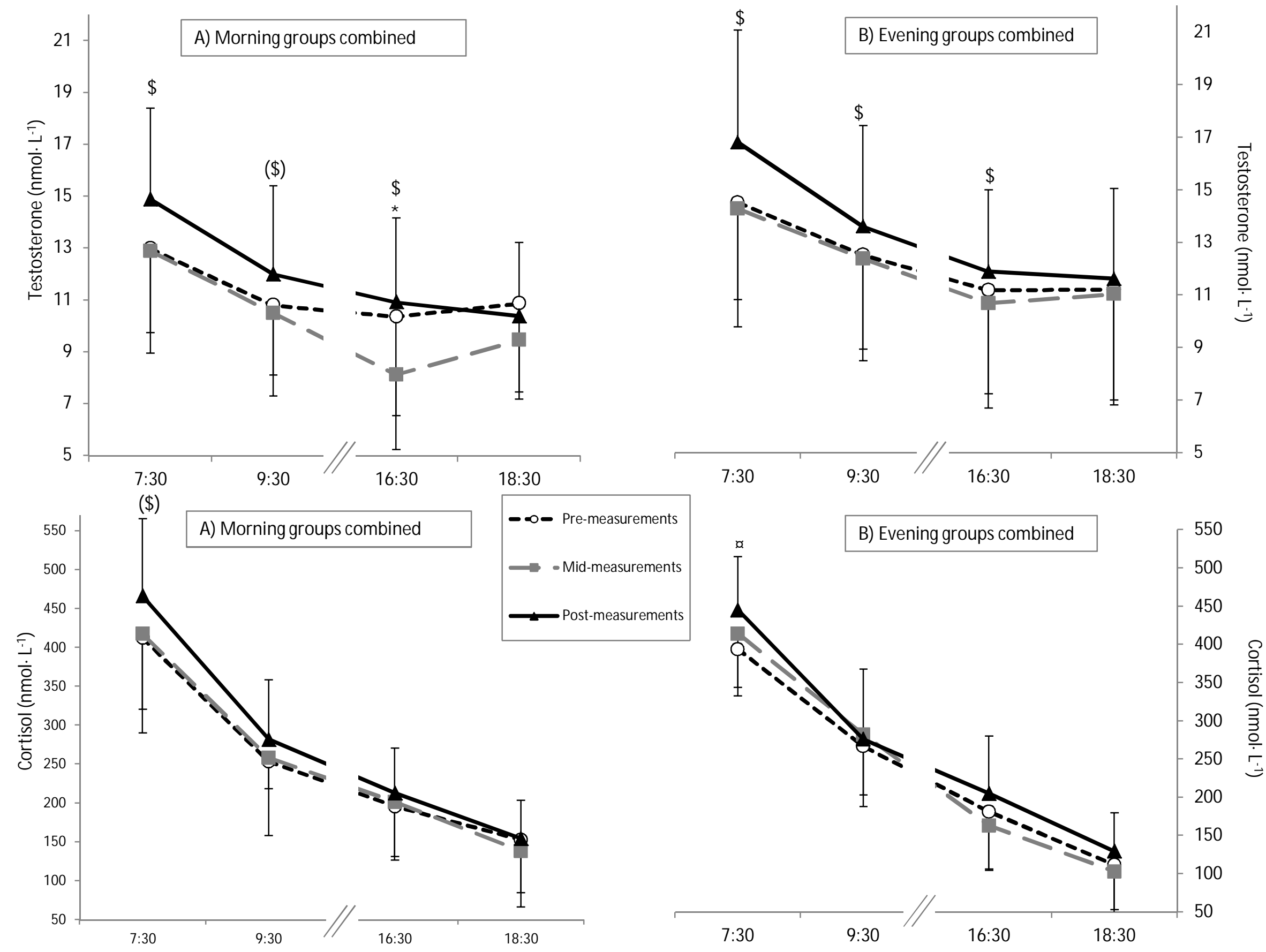

Figure 4. 